\section{Factors leading to lens implant decentration and exchange}

\section{Abstract}

Purpose To examine the intra- and postoperative factors leading to posterior chamber intraocular lens (IOL) decentration in patients requiring IOL exchange, and to identify avoidable causes of IOL decentration. Methods Case records of 17 patients who had undergone posterior chamber IOL exchange were examined for: (i) any complication or alteration to the original intended surgical procedure, (ii) IOL type and position at the completion of initial surgery, (iii) IOL position at the time of re-operation.

Results The decentred lens implants were injected silicone plate-haptic IOLs in $\mathbf{1 0}$ patients, small $(5.5 \mathrm{~mm})$ optic diameter PMMA IOLs in 4 patients and large $(7 \mathrm{~mm})$ optic diameter PMMA IOLs in 3 patients. In all cases, decentration was due to IOL subluxation. Early decentration of the injected lenses was due to IOL implantation in eyes without a continuous capsulorrhexis. In contrast late decentration was due to subluxation associated with capsule fibrosis. Decentration of small optic PMMA IOLs was found to be associated with an anterior capsule tear and haptic malposition in the ciliary sulcus. Decentration of large optic PMMA IOLs was associated with posterior displacement of one haptic through a posterior capsule defect, zonule dehiscence or fixation of one haptic in the sulcus and one in the capsule bag.

Conclusion Clinically significant postoperative subluxation of injected silicone IOLs may be minimised by implanting only into a lens capsule bag with an intact capsulorrhexis. The risk of decentration of small optic PMMA IOLs may be minimised by positioning the haptics at $90^{\circ}$ to any capsulorrhexis tear. After cataract surgery complicated by posterior capsule rupture or zonule dehiscence, it is important to assess the remaining capsule support and, where sufficient, implant a large optic diameter posterior chamber IOL in the ciliary sulcus.

Key words Decentration, Implant, Lens
The feasibility of cataract removal through a small incision has prompted the development of new designs of IOL which can be implanted through that incision and fall into two main classes. The first are flexible lenses which are either injectable or foldable, implanted through 3.0-3.5 mm wounds, and the second are small optic diameter rigid IOLs implanted through a $5 \mathrm{~mm}$ wound. In addition to small optic diameter, these IOLs have a small extended haptic diameter, typically $12.5 \mathrm{~mm}$, requiring fixation in the capsule bag. These are more likely to cause clinically significant decentration than the large optic diameter PMMA IOLs previously in wider use.

Posterior chamber IOL exchange has been shown to be a safe and generally successful procedure. However, in some cases lens exchange is a complex procedure, involving difficult IOL separation from fibrosed capsule and possible anterior vitrectomy, and patient satisfaction following surgery cannot be ensured. A range of indications for lens exchange, including decentration symptoms, incorrect IOL power and chronic inflammation have been described with favourable outcomes. ${ }^{1,2}$ The most frequently reported indication for IOL exchange is clinically significant decentration. In this study we examined the causes of decentration, in particular any intra-operative risk factors, in an attempt to reduce the incidence of this postoperative complication and requirement for IOL exchange.

\section{Methods}

Case records of patients undergoing IOL repositioning or exchange for symptoms of decentration of the posterior chamber IOL were reviewed. Any complication evident during the initial cataract extraction procedure which might be associated with post-operative IOL decentration was noted. The alteration of surgical technique to manage the complication, interval to onset of symptoms of decentration, management of IOL displacement and final visual acuity were recorded.
M.J. Tappin

D.F.P. Larkin

Moorfields Eye Hospital

London, UK

D.F.P. Larkin

Moorfields Eye Hospital

City Road

London EC1V 2PD, UK

Tel: $+44(0) 2075662045$

Fax: +44 (0)207566 2972

Received: 23 December 1999 Accepted in revised form: 14 April 2000 
Table 1. Decentred plate haptic injected silicone IOLs

\begin{tabular}{|c|c|c|c|c|}
\hline $\begin{array}{l}\text { Age } \\
\text { (years) }\end{array}$ & $\begin{array}{c}\text { Final } \\
\text { VA }\end{array}$ & $\begin{array}{l}\text { Alteration to procedure } \\
\text { at first operation }\end{array}$ & $\begin{array}{l}\text { Reason for decentration } \\
\text { of IOL at re-operation }\end{array}$ & Surgical management \\
\hline 70 & $6 / 6$ & Uncomplicated phacoemulsification & $\begin{array}{l}\text { One plate haptic anterior to } \\
\text { anterior capsule }\end{array}$ & $\begin{array}{l}\text { Exchange for } 7 \mathrm{~mm} \\
\text { sulcus-fixed IOL }\end{array}$ \\
\hline 25 & $6 / 36$ & $\begin{array}{l}\text { Incomplete capsulorrhexis, } \\
\text { inferior zonule dehiscence }\end{array}$ & Injectable silicone IOL in sulcus & $\begin{array}{l}\text { Exchange for } 7 \mathrm{~mm} \\
\text { sulcus-fixed IOL }\end{array}$ \\
\hline 84 & $6 / 9$ & $\begin{array}{l}\text { Large capsulorrhexis, } \\
\text { obscured by pupil margin }\end{array}$ & $\begin{array}{l}\text { One plate haptic anterior } \\
\text { to anterior capsule }\end{array}$ & $\begin{array}{l}\text { Exchange for } 7 \mathrm{~mm} \\
\text { sulcus-fixed IOL }\end{array}$ \\
\hline 76 & $6 / 5$ & $\begin{array}{l}\text { Tear in capsulorrhexis; } \\
\text { injectable IOL in bag }\end{array}$ & Only one IOL haptic in bag & $\begin{array}{l}\text { Exchange for } 7 \mathrm{~mm} \\
\text { sulcus-fixed IOL }\end{array}$ \\
\hline 50 & $6 / 6$ & Tear in capsulorrhexis & Only one IOL haptic in bag & IOL repositioned \\
\hline 78 & $6 / 9$ & Uncomplicated phacoemulsification & $\begin{array}{l}\text { Capsule fibrosis; injectable IOL } \\
\text { dislocated anterior to capsulorrhexis }\end{array}$ & Exchange for AC IOL \\
\hline 54 & $6 / 6$ & Uncomplicated phacoemulsification & $\begin{array}{l}\text { Capsule fibrosis; IOL dislocation } \\
\text { in anterior chamber }\end{array}$ & $\begin{array}{l}\text { Exchange for } 7 \mathrm{~mm} \\
\text { sulcus-fixed IOL }\end{array}$ \\
\hline 56 & $6 / 6$ & Uncomplicated phacoemulsification & Capsule fibrosis; IOL dislocation & $\begin{array}{l}\text { Exchange for } 7 \mathrm{~mm} \\
\text { sulcus-fixed IOL }\end{array}$ \\
\hline 73 & $6 / 6$ & Uncomplicated phacoemulsification & $\begin{array}{l}\text { PC thickening at } 3 \text { months } \\
\text { post-operatively; IOL displaced }\end{array}$ & $\begin{array}{l}\text { Exchange for } 7 \mathrm{~mm} \\
\text { sulcus-fixed IOL }\end{array}$ \\
\hline 77 & $6 / 9$ & Uncomplicated phacoemulsification & $\begin{array}{l}3 \text { months post-operatively, } \\
\text { subluxation of one plate haptic } \\
\text { into superior sulcus }\end{array}$ & $\begin{array}{l}\text { Inferior zonule dialysis } \\
\text { when IOL removed; } \\
\text { exchange for AC IOL }\end{array}$ \\
\hline
\end{tabular}

VA, visual acuity; IOL, intraocular lens; AC, anterior chamber; PC, posterior chamber.

\section{Results}

Between 1997 and 1999, IOL repositioning or exchange procedures were performed on 17 patients with clinically significant decentration. In the primary procedure, an injected plate haptic IOL was implanted in 10 patients, a $5.5 \mathrm{~mm}$ optic diameter PMMA lens in 4 patients, and a $7 \mathrm{~mm}$ optic diameter PMMA IOL in 3 patients.

\section{Silicone foldable IOLs}

The injected implants were all silicone plate haptic IOLs ('Phacoflex', Chironvision C11UB) and patient details are shown in Table 1. Two patients had an IOL placed in the bag with an incomplete capsulorrhexis. One patient had the IOL placed in the ciliary sulcus rather than the capsule bag; the visual outcome was only $6 / 36$ as the eye had undergone retinal re-attachment surgery for detachment involving the macula 1 year previously, successfully treated with a silicone explant. One patient had a very large but continuous capsulorrhexis. One patient was found at the immediate post-operative examination to have one haptic anterior to the capsulorhexis. Five patients presented 2-3 months postoperatively with sudden onset of visual disturbance. In this group who presented late following apparently uncomplicated surgery, there was unusually severe capsular fibrosis and IOL anterior dislocation through the capsulorrhexis.

Table 2. Decentred PMMA $5.5 \mathrm{~mm}$ optic diameter IOLs

\begin{tabular}{lll}
\hline $\begin{array}{c}\text { Age } \\
\text { (years) }\end{array}$ & $\begin{array}{c}\text { Final } \\
\text { VA }\end{array}$ & $\begin{array}{l}\text { Alteration to procedure } \\
\text { at first operation }\end{array}$ \\
\hline 52 & $6 / 5$ & Capsulorrhexis tear \\
89 & $6 / 12$ & $\begin{array}{l}\text { Radial capsulorrhexis tear } \\
85\end{array}$ \\
$6 / 12$ & $\begin{array}{c}\text { Radial capsulorrhexis tear, } \\
\text { phacoemulsification } \\
\text { converted to ECCE } \\
\text { Capsulorrhexis tears, } \\
5.5 \text { mm IOL in bag }\end{array}$ \\
\hline
\end{tabular}

\section{Small optic PMMA IOLs}

In 3 patients, decentration of $5.5 \mathrm{~mm}$ optic diameter IOLs (Chironvision MC550) was found to be associated with a radial capsulorrhexis tear after phacoemulsification. At re-operation in all these cases, one of the haptics was found to be in the ciliary sulcus through the capsule tear (Table 2). In one of these patients, a $5.5 \mathrm{~mm}$ IOL was implanted following conversion from phacoemulsification to extracapsular cataract extraction (ECCE) on account of a radial capsulorrhexis tear.

\footnotetext{
VA, visual acuity; IOL, intraocular lens; ECCE, extracapsular cataract extraction.
} 
Table 3. Decentred $7 \mathrm{~mm}$ optic diameter PMMA IOLs

\begin{tabular}{|c|c|c|c|c|}
\hline $\begin{array}{l}\text { Age } \\
\text { (years) }\end{array}$ & $\begin{array}{c}\text { Final } \\
\text { VA }\end{array}$ & $\begin{array}{l}\text { Alteration to procedure } \\
\text { at first operation }\end{array}$ & $\begin{array}{l}\text { Reason for decentration } \\
\text { of IOL at re-operation }\end{array}$ & Surgical management \\
\hline 80 & $6 / 36$ & Posterior capsule tear & $\begin{array}{l}\text { IOL displaced posteriorly } \\
\text { through tear }\end{array}$ & Exchange for AC IOL \\
\hline 76 & $6 / 12$ & Uncomplicated ECCE & $\begin{array}{l}\text { One haptic in sulcus, } \\
\text { one in bag }\end{array}$ & IOL repositioned in sulcus \\
\hline 75 & $6 / 18$ & $\begin{array}{l}\text { Inferior zonule dehiscence, } \\
\text { vitreous loss, sulcus-fixed IOL }\end{array}$ & $\begin{array}{l}\text { Inferior displacement of } \\
\text { IOL by vitreous wick }\end{array}$ & $\begin{array}{l}\text { Repositioning of IOL } \\
\text { in sulcus }\end{array}$ \\
\hline
\end{tabular}

VA, visual acuity; IOL, intraocular lens; ECCE, extracapsular cataract extraction; $\mathrm{AC}$, anterior chamber.

\section{Large optic PMMA IOLs}

There were three decentred $7 \mathrm{~mm}$ optic diameter PMMA IOLs (Chironvision 6840U). In one patient this was due to posterior dislocation of one haptic through a posterior capsule tear; the visual outcome was only 6/36 due to age-related macular degeneration. Decentration in a second was due to IOL displacement in a sector of zonule dehiscence; visual acuity at the last review was $6 / 18$, the assumed cause being subclinical cystoid macula oedema due to complicated surgery. IOL decentration in a third patient followed an uncomplicated ECCE procedure; one haptic was found in the capsule bag and the other in the sulcus ('hybrid' fixation). Management at re-operation is detailed in Table 3.

\section{Discussion}

Decentration of IOLs may lead to symptoms of monocular diplopia, glare and deterioration of visual function. $^{2-4}$ The relatively small optic diameter of many of the lens implants in current use in small-incision cataract surgery increases the likelihood of decentration symptoms if that lens is malpositioned. The exchange of posterior chamber IOLs has been shown by several authors to be a safe and effective method of managing these complications. ${ }^{1,2}$ Walkow and co-authors ${ }^{4}$ reported zonule dehiscence and asymmetric implantation as peroperative causes of IOL decentration. Ram and coworkers ${ }^{5}$ have demonstrated on a large series of cadaver eyes that asymmetric, or hybrid, implantation

(bag-sulcus) leads to a significantly greater degree of decentration. This series identifies additional avoidable per-operative risk factors for decentration of IOLs. We suggest that appropriate management of per-operative complications and correct choice of IOL can minimise the risk of IOL decentration symptoms.

Of those patients presenting with early post-operative decentration (within 1 month), with the exception of one of the silicone plate haptic IOL recipients, decentration was due to inappropriate use of a small-diameter IOL either implanted in the capsule bag with incomplete capsulorrhexis or implanted in the sulcus. In these circumstances, the use of a rigid large optic IOL was indicated. The finding in one patient of IOL subluxation post-operatively in association with an unusually large capsulorrhexis suggests that the flexible silicone plate haptics require a significant rim of anterior capsule to stabilise optic position in the bag. In patients in whom there is a large capsulorrhexis, there may be an advantage in rotating the plate haptics to a meridian in which they are better supported by anterior capsule.

Late subluxation of silicone plate haptic IOLs occurred between 2 and 3 months post-operatively in patients in whom surgery was uncomplicated, and in whom good post-operative vision and satisfactory IOL position were reported at 1 month. Acute onset of visual disturbance is of particular interest in this group and probably caused by capsule shrinkage causing flexion of the IOL and acute expulsion of one haptic from the capsular bag. ${ }^{6}$ The incidence of capsular contraction has been shown to be greater in diabetic patients ${ }^{7}$ and patients with retinitis pigmentosa. ${ }^{8}$ Capsular contraction has also been described in patients with uveitis and pseudoexfoliation syndrome. ${ }^{9}$ It is therefore advisable to avoid the use of plate haptic lenses in patients with such conditions which increase the risk of an exaggerated capsular contraction. In our series, however, none of the patients with late subluxation of plate haptic IOLs had any of these risk factors.

Incidence of late subluxation of plate haptic lenses due to capsular contraction may be reduced by modification of the lens design by enlarging the haptic dialling holes, enabling adhesions to form between anterior and posterior capsule. On the other hand, where further surgery is necessary, these anterior to posterior capsule adhesions make any future IOL manipulation more difficult.

The injected IOL with a haptic diameter of $10.5 \mathrm{~mm}$ requires support by a continuous capsulorrhexis. ${ }^{3}$ In cases in which there is discontinuity in the capsulorrhexis, the high likelihood of decentration of flexible silicone IOLs necessitates implantation of a PMMA IOL, either a sulcus-fixed $13.5 \mathrm{~mm}$ haptic diameter or a bag-fixed $12.5 \mathrm{~mm}$ haptic diameter lens. However, decentration has been reported in the latter circumstances $^{2,10}$ and the series reported here also highlights the risk of implanting such an IOL with an incomplete capsulorrhexis. To avoid displacement of one haptic through the capsule tear into the ciliary sulcus we recommend orientation of the haptics so they lie at $90^{\circ}$ to a radial capsulorrhexis tear. In the less common circumstance of more than one tear in the capsulorrhexis, implantation of a large optic IOL with extended haptic diameter of $13.5 \mathrm{~mm}$ in the sulcus is indicated. The disadvantage of wound extension to $7 \mathrm{~mm}$ is outweighed by a well-centred IOL, the larger optic diameter of which reduces to negligible the risk of decentration symptoms. 
Decentration of large optic PMMA IOLs was less common in this series, and found to be associated with (i) inadequate capsule support following a posterior capsule tear, (ii) zonule dehiscence and (iii) positioning of only one haptic in the capsular bag. With capsular fibrosis even a lens optic of $7 \mathrm{~mm}$ can become decentred, but this risk is minimised if both haptics are placed symmetrically in the sulcus. ${ }^{11}$

In conclusion, we emphasise the importance of implanting the correct type of IOL in the event of capsulorrhexis or posterior capsule tears, and specifically avoiding silicone plate haptic IOLs. The use of small optic PMMA IOLs in the presence of anterior capsule tears can also lead to decentration, but this risk may be reduced by rotating the haptics to lie at $90^{\circ}$ to the tear. If there is any doubt as to the stability of an IOL, current best practice is to implant a large optic and haptic diameter PMMA IOL in the ciliary sulcus.

\section{References}

1. Sinskey RM, Amin P, Stoppel JO. Indications for and results of a large series of intraocular lens exchanges. J Cataract Refract Surg 1993;19:68-71.
2. Calson AN, Stewart WC, Tso PC. Intraocular lens complication requiring removal or exchange. Surv Ophthalmol 1998;142:417-36.

3. Cumming JS. Surgical complications and visual acuity results in 536 cases of plate haptic silicone lens implantation. J Cataract Refract Surg 1993;19:275-7.

4. Walkow T, Anders N, Pham DT, et al. Causes of severe decentration and subluxation of intraocular lenses. Graefes Arch Clin Exp Ophthalmol 1998;236:9-12.

5. Ram J, Apple D, Visessook N, et al. Update on fixation of rigid and foldable posterior chamber intraocular lenses: 1 . Ophthalmology 1999;106:883-90.

6. Kohnen T. Complications and complication management with foldable intraocular lenses. [editorial]. J Cataract Refract Surg 1998;24:1167-8.

7. Hayashi H, Hayashi $\mathrm{K}$, Nakao F, et al. Area reduction in anterior capsule opening in eyes of diabetes mellitus patients. J Cataract Refract Surg 1998;24:1105-10.

8. Hayashi K, Hayashi H, Matsuo K. Anterior capsule contraction and lens dislocation after implant surgery in eyes with retinitis pigmentosa. Ophthalmology 1998;105:1239-43.

9. Davison J. Capsule contraction syndrome. J Cataract Refract Surg 1993;19:582-9.

10. Ulrich FC, Legler MD, Ehud I, et al. Prospective experimental study of factors related to posterior chamber intraocular lens decentration. J Cataract Refract Surg 1992;18:449-55.

11. Assia RI, Legler UFC, Meril C, et al. A clinicopathologic study of the effect of radial tears and loop fixation on lens decentration. Ophthalmology 1993;100:153-8. 